\title{
Cisneros y el Norte de Africa
}

\author{
Miguel Avilés Fernández \\ Catedrático de Ilistoria Morlerna de la Universidad Nacional \\ de Educación a Distancia, Madrid
}

Constituye para mí un gran motivo de satislacción el que se hayan convocado estas III Jornadas sobre la Presencia española en el Norte de Africa, gracias a la entusiasta dedicación de la Dirección Provincial del Ministerio de Cultura de la Ciudad de Melilla y, muy particularmente, de su titular y de su eficaz equipo de colaboradores. Estas iniciativas, al repetirse de una manera periódica, están contribuyendo a que los estudiosos de la Península fijen cada vez más su atención en este interesante mundo nortealricano.

Si de alguna forma es cierto que los intelectuales están en condiciones de influir sobre la opinión pública, también podremos vislumbrar la popularización del interés por el Vorte de Africa, entre cuyas ciudades se encuentran dos preciadas porciones del universo hispánico, como ocurre con esta ciudad de Melilla que hoy nos acoge.

No menos satisfactorio es, para mí. el haber sido invitado para pronunciar la ponencia de apertura de estas Jornadas. Personalmente, me agrada volver a encontrarme entre ustedes y rememorar los gratos momentos vividos en anteriores ocasiones. También me congratulo de pertenecer como prolesor a la Lniversidad Nacional de Educación a Distancia, cuyo Centro Asociado de Melilla hace presente aquí a la Universidad española.

Este acto de presencia personal e institucional tiene un especial significado en un Congreso dedicado a estudiar la presencia española 
en el Norte de Africa. En realidad, alirma esa presencia en ol momento actual y muestra una seria voluntad de presencia de cara al futuro. Pero. como esa presencia hunde sus raíces en el pasado, yo quisiera también, como historiador, reforzar la realidad y el futuro de esta presencia mirando hacia el pasado.

La presencia de Europa y; desde luego, de los hombres de la Península Ibérica en el Norte de Africa, bien puede remontarse en la historia hasta perderse en la tópica noche de los tiempos. Los antecedentes próximos de la actual presencia, sin embargo, se sitúan en el otoño de la Edad Media y en los albores de la Modernidad, campo al que dedicamos nuestras investigaciones como historiador.

Por eso, la ponencia que espero desarrollar ante su benévola atención se centrará, precisamente, en esa coyuntura histórica y, dentro de ella, atenderá a profundizar en la biografía de uno de los españoles que más hondamente han sido afectados por la vocación africanista, un hombre que, entre sus numerosas y gravísimas responsabilidades, tuvo su corazón apasionadamente orientado hacia el Africa y puso al servicio de esa pasión toda su inteligencia, su perspicacia. sus múltiples habilidades, su comprobada eficacia, su tiempo, sus tesoros y sus amigos y servidores.

Nos estamos refiriendo a Fr. Francisco Jiménez de Cisneros, aquel franciscano que, como reza el epitafio que compuso para él el humanista Juan de Vergara, unió la púrpura con el sayal frailuno, el yelmo con el capelo y la corona con la cogulla franciscana y que, en todas sus dimensiones, como hombre público y como hombre privado, tuvo ante sus ojos una sublime obsesión: la de incorporar a la Corona de España las tierras africanas que baña el Mediterráneo.

Hasta hace bien poco tiempo, no estaba de moda hablar de Cisneros, como no lo estaba hablar de los Reyes Católicos o de los Reyes de la Casa de Austria. El que, en determinada época de la historia de España, -bien reciente por otra parte-, se hubieran identificado determinados intereses políticos e ideológicos con la obra de estos gobernantes, se tradujo en un cierto desapego de los historiadores hacia la investigación sobre aquellos sus ticmpos. Hoy día, cuando en España se ha vuelto a caminar, ahora resueltamente, por senderos de democracia y cuando se aproximan importantes efemérides relacionadas con la gestión política de aquellos gobernantes, el interés por su historia está resurgiendo a ojos vistas. 
Es de esperar que no sean sólo los historiadores los que se entreguen confiadamente al estudio de aquella coyuntura. Es de creer que nuestro pueblo incorpore a su culuura global, sin iras ni nostalgias, las realidades que entonces tomaron cuerpo y, todavía hoy, siguen influyendo, de una u otra forma, en nuestra realidad presente. Y es de desear que, además de las iras y las nostalgias, se deseche también un cierto complejo colectivo. el complejo que yo denomino nacional-masoquisla, que nos lleva con frecuencia a complacernos en los aspectos más negativos de nuestro pasado, en vez de asumirlos como parte del mismo y de aceptarlos dignamente. como se acepta a los padres, con sus virtudes y con sus defectos, sin sentirse obligados a renegar vergonzantemente de ellos ante propios y extraños.

\section{PASAR AL AFRICA, UNA OBSESION DE CIBNBROS}

Por estos motivos nos hemos atrevido a hablar hoy de (iisneros y de su acción sobre $\Lambda$ frica, no para complacernos en la violencia que conllevó la conquista, ni para congratularnos con sus victorias o con llorar sus fracasos, sino para tratar de entender los motivos que tuvieron, tanto Cisneros como quienes compartieron sus puntos de vista, para hacer lo que hicieron, para conocer y comprender las consecuencias de sus proyectos y de sus fracasos, para aprender, en último término, hasta qué punto se parece nuestro presente a su pasado y para comprobar si en nuestros proyectos presentes hemos asumido las lecciones del pasado de modo que no caigamos en parecidos errores y desorientaciones.

Así pues, entremos en el estudio de lo que significó Africa para Cisneros. Para acertar en nuestra pesquisa hemos recurrido a las noticias que, sobre el mismo, nos da uno de sus primeros biógrafos y uno de los autores que más se afanó por reúnir toda la información precisa para trazar su perfil como hombre y como gobernante.

Vos referimos a Alvar Gómez de Cástro, autor de una importantísima obra titulada De rebus gestis a Francisco Ximenio Cisnerio (1). Aunque esta extensa obra nos informa detalladamente desde todos los puntos de vista, de la vida y los hechos del Cardenal Jiménez, nosotros nos limitaremos a espigar en ella solamente aquello que nos sea útil para conocer lo que significó para Cisneros el mundo al ricano.

Ya en otra ocasión hemos resaltado la existencia de una obsesión común entre los místicos españoles: el deseo de ir a tierra de moros. 
para evangelizarlos y convertirlos, aun con el peligro de perder la vida en el intento. Esa tierra de moros constituye un imaginario geográfico que lo mismo puede entenderse como la Tierra Santa, sometida al poder del Islam, como cualquier otra tierra dominada por los musulmanes, especialmente las tierras más próximas a la Península Ibérica, es decir, las del Norte de Africa, camino obligado, por otra parte, para llegar por tierra hasta los Santos Lugares. Hemos detectado esa obsesión tanto en Raimundo Lulio como en Pedro Fernández Pecha, el lundador de los Jerónimos, en san Ignacio, en santa Teresa y en una multitud amplísima de figuras mayores y menores de nuestra constelación mística (2).

Cisneros no fue, desde luego, una excepción. sino, incluso, el paradigma de los espirituales obsesionados por ir a esa imprecisa tierra de moros, que, en el caso de Cisneros, tuvo perfiles extraordinariamente definidos.

Ya en sus primeros tiempos como provincial de los franciscanos de Castilla, tuvo ocasión de viajar, visitando los conventos de su orden, hasta Gibraltar. Se nos cuenta cómo, al contemplar desde allí las costas del continente vecino. "atraído por la vista de Africa y porque mucho tiempo hacía estaba deseando pasar allá... comenzó a pensar en un viaje por mar" (3). Jiménez, como nos cuenta su biógralo, "ardía en vivos deseos de anunciar a Cristo a los hombres de ultramar, dispuesto al mismo tiempo a sufrir suplicios y muerte".

No llegó, sin embargo, a realizar aquel proyecto. Antes de embarcarse, le aconsejaron que fuera a consultar a una beata, "famosa por su santidad de vida" de la que se creía que "gozaba frecuentemente de visiones celestiales". Cisneros le pidió su parecer y la buena beata "lo disuadió... porque, decía, él estaba reservado para realizar grandes hazañas, en las que habría de sostener muchas más duras que si se hallara entre naciones bárbaras y africanas". Así pues, "desanimado por las palabras de la beara, cambió de parecer y regresó desde la Bética a Castilla" (4).

Con el tiempo, Cisneros no cambió de parecer, aunque acomodó su antiguo proyecto a las circunstancias en que la vida le lue situando, como pronto tendremos ocasión de ver. En efecto, conforme fue escalando las cumbres del poder eclesiástico mediante su acceso al Arzobispado de Toledo y del poder político, con su llegarda al cargo de regente del Reino, los sueños juveniles do evangelización pacílica se convirtieron en la apasionada obsesión del hombre maduro por conquistar las tierras ocuparlas por el Islam, cmpezando, desde luego, por las próximas tierras de Africa. Para él. 
que dejó fama de comportarse en todo momento con extraordinaria prudencia. hubo algunos temas en los que no se dejó llevar por la prudencia. sino por la pasión. Lino de ellos lue. precisamente. el de la conquista de Africa (j). En nuestra opinión. sin embargo, aquella obsesión suya por la conquista de Alrica no constitúa un fin en sí misma, sino que era un medio necesario para lograr otros objetivos mucho más amplios y generales. La conquista sería un paso necesario para lograr la conversión de todos los infieles. Entonces, se realizaría el viejo sucño de unir a toda la grey humana bajo una misma ley y un mismo pastor:

\section{UNA GREY Y UN PABTOR BOLO EN RL SUELO}

Esta idea es familiar a todos los que conocen aquel famoso soneto de Hernando de Acuña, dedicado al Emperador Carlos V, que reza así:

la se acerca. señor; o es ya llegada

la edad gloriosa en que promete el cielo una grey y un pastor sólo en el suelo...

... un monarca. "un imperio y una espada (6).

Sin embargo, bastantes años antes de que Acuña compusiera su soneto. ya debía ser tan sabido. en el entorno de Cisneros, que este tema le entusiasmaba que, cuando se inauguró la Universidad de Alealá de Henares, el encargado de pronunciar el discurso de apertura, Hernán Alonso de Herrera, regaló los oídos de Cismeros con estas palabras:

;Oh dichosos los siglos presente y venideros, que de hoy. más beberín aguas puras y vivas de santa teología en sus primeros manantiales! ;Oh tres y cuatro veces bisnaventurado tan esclarecido primado de las Lspañas, a quien Dios dio tanla gracia que tres lenguas nobles en quien esta puesto el tesoro de los divinales sacramentos, las juntásedes en uno! Asaz manifiesta muestra del milagro que muchos creen que anda Dios rodeando de hacer, por mestm mano, que vos, cristianisimo prelado, con el poder de Dios, lo hagáis todo ano: ana ley; una grey. yn pastor (?). 
Era esta una idea muy simple, como simples y claras pueden ser las grandes obsesiones. Cisneros debía repetirla a diestro y siniestro. como suprema justificación de sus mayores empresas. Así lo entendió el rey don Manuel de Portugal, a quien Cisneros escribió una larga carta proponiéndole unir sus ejércitos a los de Fernando de Aragón y a los de Enrique de Inglaterra, para hacer realidad la conquista de Jerusalén. A la vista de aquella carta. Manuel el Afortunado nos dejó una clara prueba de la medida en que aquella idea estaba constantemente en el punto de mira de Cisneros.
Por lo que de lit carta se desprende, -le escribia-, tus deseos siempre lienden a que desaparezca la secta mahometana y se unan por fin a la grey cristiana cuan- tos están fuera de la congregación de los cristianos y se haga un solo rebaño y un solo pastor (\$).

La idea de esta expedición para recuperar los Santos Lugares era, sin duda, grandiosa. La vieja aspiración de todos los Cruzados la sentía ahora Cisneros al alcance de los Reyes de su época. Su carta a los reyes de Portugal, Inglaterra y España no era una simple declaración de principios, sino un plan detallado hasta el punto de sorprender a sus destinatarios. El propio Manuel de Portugal lo reconocía palmariamente:

Tú, óplimo obispo, presentas un cuidado ciertamente no ordinario ni vulgar y me ofreces una prueba nada mediocre de II" gran solicitud, cuando te manifiestas tan enterado de todo cuanto conduce a realizar tal empresa. Pues no hay en oriente marino alguno que pueda señalar con más claridad y exachilud los folfos del mar, las ensenadas para las naves y los escollos que se ocultan enmedio del mar: Lo que indicas sobre el modo de llevar a cabo la guerra, está dispuesto tan apta y convenientemente, lan intrépida y sólidamente que parece que no te dedicas a olra cosa. Por lo cual, aunque tratemos de esto más tarde y, aunque no hemos de discutir o decidir sobre ello antes de que, examinadas todas las cosas como conviene, nos pronunciemos lambién nosotros 
sobre el particular, hemos querido exponértelo brevemente, y que hemos sido provocados por li de morlo tan elegante (9).

\section{EL HORIZONTE DF JBRUSALFN}

Aquel fantástico. pero detallado proyecto, munca se realizó. Pero no cabe duda de que Cisneros debió soñar con la escena que el propio rey de Portugal describiría, en la misma carta a que nos venimos refiriendo, con estas palabras:

Esperamos que por estu feliz y fausta expedición, todo ello se conseguirá com creces; tanlo que, promlo, cuando gozoso por las victorias alcanzadas, celebres la misa jumto al sépulero del Señor: nosolros, suegro y los dos yernos, inundados de alegria y de placer, hemos de recibir de lus manos, de rodillas, ol sncrosano Cuerpo de Cristo (10).

Al no poder verificarse a corto plazo estos propósitos finales, Cisneros los interiorizó de distintas maneras. Por una parte concibió el progreso en la vida espiritual como un inimerrumpido caminar hacia la Jerusalén celestial. Así se lo hizo saber claramente a los canónigos de Toledo. cuỵas vidas, un tanto disipadats, trató de concauzar por mejores sendas. los reunió a todos en su palacio y. emure otras cosas, les dijo lo siguiente:

Os hablaré con franqueza: por mi parle, a cuanlos observe que, subiendo por este camino hacia derusalén del cielo van aranzando de virtud en virlud. los apoyaré sin ducla, no sólo en sus intentos, sino que incluso los colmaré de utilidades y dignidad (11).

Por otra parte anmue no pudo realizar de inmediato su idea de celebrar sobre el mismo sepulcro de Ciristo, ocurrió un feliz incidente que le permitió hacer cotidianamente algo muy parecido a lo que se había propuesto como objetivo final. Ocurrió que el sultán de ligipto. sintiéndose amenazado por el creciente poderío turco. pensó en enviar una embajada 
pidiendo ayuda a los más poderosos principes cristianos. Eligió para llevarla a cabo a un franciscano, guardián de los santos lugares. Esice tuvo la ocurrencia de tomar consigo "una lápida de mámol de tres pies de largo y uno de ancho, salpicada de manchas azuladas" que se encontraba colocada junto al sepulcro de Cristo. La partió en cinco trozos e hizo que cada uno de ellos fuera convertido y consagrado como ara de altar. Cion aquel regalo en su equipaje, el embajador del sultán fue haciendo su recorrido y dejando a cada destinatario cada una de aquellas aras. Recibieron tal regalo el papa Alejandro VI. Isabel la Católica. Manuel de Portugal y el Cardenal de Santa Cruz de Jerusalén. don Bernardino de Carvajal. La quinta ara la entregó a Cisneros. Este,

que había puesho todo su gozo en la celebración del sagrado misterio, cuando obturo aquella ara procedente del sepulcro del Señor, estaba exullante de alegría; durante los doce años que aún vivió, nunca celebró la divina Eucaristía en otro sitio que en aquella ara, permitiendo también a los franciscanos que le acompañaban hacer to mismo. A su muerte, según consta en su teslamento, la legó a la Iglesia de Toledo (12).

Podríamos creer: a la vista de lo dicho, que Cisneros interiorizó su frustrada ansia de conquistar los Santos Lugares convirtiendo la vida espiritual en una peregrinación simbólica a Jerusalén o sustituyendo su deseo de celebrar sobre la losa sepulcral de Cristo celebrando sobre el ara que le regaló el embajador del sulıán. Con extraordinario realismo, Cisneros se puso en camino hacia Jerusalén desde el momento en que puso toda su inteligencia. sus poderes y su entusiasmo en la conquista física del litoral africano. Lo que más se pudo admirar de él. como diría su biógrafo, fue el que "nacido para labrar la salvación y felicidad de la sociedad, se preocupó durante toda su vida de esto sólo: hacer nuestras aquellas costas africanas" (13).

Cisneros, por otra parte, no estaba solo en este propósito. Tanto la Reina Isabel, mientras vivió, como Fernando el Católico, coincidian con Cisneros en aquella misma lijación. Fernando y Jiménez, se nos cuenta, "se habían propuesto someter al imperio español la costa marítima de Africa y aun toda la región de Mauritania” (14). Inmediatamente des- 
pués de la conquista de Orán comentando lo sucedido ante sus íntimos, Cisneros confesó. "Si me hubjeran dado un ejército liel, yo habría conseguido una victoria completa conquistando no sólo Orán, sin toda el Africa, aun con el cuerpo cansado" (15). Para él, en realidad, la conquista de Africa no era más que un episodio de algo mucho más importante: "En esta lucha: dijo-, pelean Cristo, Hijo de Dios Padre, y Mahoma, seductor de los árabes. Y creo, -añadió-, que toda tardanza es no sólo perjudicial, sino también sacrílega" (16).

\section{LA GRUZADA DY ORANT}

La historia de la conquista de Africa que, en aquellos años en que se alternaron en el poder Fernando el Católico y Cisneros, llevó a los españoles desde el Peñón de Vélez de la Gomera hasta Trípoli, es suficientemente conocida como para eximirnos en esta ocasión de repetirla. Vamos a recorrerla, sin embargo, per summa capita, con la única intención de resultar la intervención de Cisneros en cada uno de los pasos que se dieron en este proceso.

La primera cabeza de puente creada en las costas de aquende fue, como es bien sabido, Melilla, ocupada en septiembre de 1497. La empresa. sin embargo, se detuvo durante unos años a causa de los compromisos contraídos por la Corona en el Reino de Nápoles. Isabel la Católica, antes de morir, encomendó en su testamento a su marido y a su hija Juana "que no cesen en la conquista de Africa e de pugnar por la fe contra los infieles" (17). Pocos meses después del fallecimiento de Isabel, ya se iniciaron los preparativos para proseguir la conquista de Africa.

El impulso definitivo parece haberse debido, en este caso, al propio Cisneros. Se nos cuenta que entró en contacto con él el mercader veneciano Jerónimo Vianello "hombre activo y conocedor de las cosas de Africa" (18). Trató con Cisneros todos los detalles de las operaciones que convenía realizar. El objetivo que le propuso el veneciano fue la conquista de Orán, pero le aconsejó que, previamente, se ocupara Mazalquivir, puerto "en el que tiene cabida una armada muy grande y en ninguna parte de toda la costa de Africa pueden los barcos estar más seguros y cómodos" (19). Inmediatamente Cisneros "aconsejó e instó al rey Don Fernando, pues tenía treguas con los franceses. procurase de echar las fuerzas del nombre cristiano contra los moros africanos" (20). EI mismo se ofreció a adelantar 
los dineros que serían necesarios para la guerra, como de hecho lo hizo hasta el punto de que, al recibirse la noticia de la victoria, lograda en septiembre de 1505. el propio Rey, acompañado de su Corte, acudió a visitar al arzobispo para agradecerle aquel generoso adelanto (21). En Mazalquivir quedó como gobernador y jefe de la guarnición don Pedro Fernández de Córdoba. Alcaide de los Donceles.

Antes de alacar a Orán, sin embargo, el esfuerzo tanto de Fernando el Católico como el de Cisneros se concentró en ampliar la presencia española en todo el litoral, a uno y otro lado de Melilla. Hacia el oeste, se ocupó Cazaza y el Peñón de Vélez de la Comera, en 1507. Al mismo tiempo. se pusieron los medios para lograr que Portugal reconociera la legitimidad de la presencia castellana en aquella costa africana. Para ello, se envió una expedición militar a levantar el sitio que el rey de Fez había puesto a Arcila. fortaleza portuguesa situada en la costa atántica. Este apoyo a la monarquía hermana motivó el que el rey de Portugal aceptara que, desde un punto situado a treinta leguas al oeste del Peñón y en dirección hacia el este, todo el territorio que se pudiera conquistar quedara en manos castellanas.

Ilacia el este, se intentó ocupar Oné, un punto intermedio entre Nelilla y Mazalquivir, pero en esta ocasión no se logró el éxito inmediato. En esla coyuntura, se produjo un desastre: el alcaide de los Donceles, enfrentado con sus tropas a los berberiscos, pereció luchando a la desesperada.

Se cuenta que "se vieron tan violentamente conmovidos y solsecogidos con tal noticia liménez y los demás principales que estaban junto a la reina Juana (todavía no había regresado Fernando de Nápoles) que Jiménez se hubiera hecho a la mar para llevar a cabo la por tanto tiempo deseada expedición” (22). Como comenta Alvar Gómez en otro lugar. "nada hirió tanto el espíriu de Jiménez como lo que le sucedió por aquellos días en Africa al Aladide de los Donceles" (23). Pero el estado del Reino le obligó a esperar una mejor coyuntura.

En 1509, finalmente, se puso en marcha el ataque general contra Orán. En todos los pueblos de España se predicó la guerra contra los infieles, para que se alistaran a ella todos los que lo desearan (24). Junto al ejército regular, aportado por el Rey. (isneros puso a disposición de aquella empresa un verdadero ejército reclutado por sus propios medios entre todas las gentes de su extensísima provincia eclesiástica. Sus propios Camiliares, entre los que descollaba Villarroel, gobernador del Adelanta- 
miento de Cazorla, se ofrecieron a participar en la guerra (25). Sabemos que colaboraron con Gisneros, en aquella ocasión, hasta tres obispos. Antonio de Acuña, el futuro obispo comunero, se encargó de preparar parte de la flota que debía transportar al Africa las tropas y los bastimentos (26). Juan de Cazalla, obispo titular de Verissa. que luego se haría lamoso como alumbrado. lo acompañó en todo momento (27). Un tercero. Bustamante, obispo titular de Hipona: no dudó en ponerse al frente de las tropas reclutadas en La Guardia, Romeral y Lillo (28). Pero la gran masa de combatientes la formaron labradores rechutados cn tierras de Toledo y Guadalajara (29).

La empresa se concibió como una verdadera Cruzada. La cruz, como símbolo de la victoria, estuvo presente en todo momento. ya desde mucho antes de que comenzaran las hostilidades. Verdaderos o falsos, se hicieron correr rumores de que habían sucedido algunos hechos maravillosos que presagiaban la victoria de las armas cristianas. Al zarpar las naves camino de $A$ frica, los que viajaban en ellas contemplaron una cruz formada en el cielo. El obispo Cazalla, contemplando aquella cruz,

dirigióse a los soldados y les dijo: 'Con esta señal venceremos: Cuando el día tres de mayo me oisteis predicar en la catedral de Toledo y os decía que nosotros íbamos al Africa a rescatar la cruz que de aquellos lugares habian arrojado impiamente los árabes, siendo su guia Mahoma, he aquí que se nos presenta en el mismo sitio y nos augura una victoria cierta (39).

La interpretación de Cazalla fue la misma que se dio a la supuesta aparición de la cruz al emperador Constantino en vísperas de la batalla de Puente Milvio contra surival Majencio. Entonces se dijo que la cruz celestial había aparecido rodeada de una inscripción "In hoc signo vinces", "con esta señal, vencerás".

Poco antes, en un lugar de Guadalajara llamado Baiona de Tajuña. "se dejó ver una cruz por algunos días". Todos los que la vieron hacían las más variadas interpretaciones sobre lo que aquella cruz podía significar. He aquí la pintoresca interpretación que dio del fenómeno uno de los lugareños de Baiona: 
Al fin un hombre, de no torpe ingenio, como parece, dijo a Cisneros alli presente: 'A ti te advierle, Prelado, para que te apresures a llevar a cabo la expedición que intentas hacer; pues comprendas que Baiona se diferencia poco de veaína. I veaina. en la lengua de los espanoles, es lo mismo que marcha pronto' (31).

Lna vez en el campo de batalla, Cisneros se hizo preceder en todo momento por la misma cruz de plata que en tiempo atrás liabía sido colocada por su predecesor, don Pedro Gonzalez de Mendoza, sobre las torres de la Alhambra, en señal de que la ciudar se había rendido a los Reyes Católicos. En esta ocasión, se encargó de llevar la cruz un franciscano de espaldas robustas y de gran estatura, que solía acompañar a Cisneros como si fuera su guardaespaldas. Detrás de él iba Cisneros, "montado en una yegua blanea, ceñida la espada al cinto sobre el hábito linuciscano, como los demás religiosos que por orden de Cisneros se hahían armado aquel día" (32). cuando la ciudad de Orán fue tomada, finalmente, Cisneros, "con la cruz delante, rodeado del ejército victorioso. entró en la ciudad" (33).

Cisneros se esforzó por afianzar la presencia española en la región por diversos caminos, no contento con el simple éxito militar. Trató de establecer colonos castellanos en las tierras conquistadas. Se esforzó también por vincular el territorio de Orán a la Diócesis de Toledo. esgrimiendo a su favor razones históricas y, sobre todo. las que le daba el haberlo conquistado con los recursos de su arzobispado (34). Para asegurar Orán desde la retaguardia española, hizo que el Arlelantamiento de Cazorla. perteneciente a la Archidiócesis de Toledo, se convirtiera en un verdadero patrono del oranesado, comprometiéndolo a asistir con recursos humanos y mantenimientos de todo tipo a la nueva conquista (35). Para lograr las mayores adhesiones a sil empresa, permitió que se trajeran deste Africa, como esclavos, muchos de los oraneses cautivados en batalla. Vuchos años después, Alvar Gómez de Castro conoció a muchos de estos cautivos que habían quedado repartidos por los más pecqueños lugares de Toledo y Guadalajara (36). Su regreso a Toledo y a Alcalá revistió la forma de un verdadero triunfo a estilo romano. En Alcalá 
Le salieron a recibir los ciudadanos y los distintos grados literarios, los cuales, con alegres saludos, le felicitaban por haber regresado sano y por su feliz victoria. Iban delante del prelado moros cautivos y camellos cargados de plata y oro, provenientes del botín de Africa, $y$ también de libros escritos en árabe, que tralaban de astrología y medicina, para enriquecer su biblioleca; cerrojos de la Alcazaba y de las puertas de la ciudady clavos y candeleros y barreños de las mezquitas, que usaban los árabes para sus abluciones, y cuernos de caza, que llamamos añafiles. Muchas de eslas cosas se colgaron en la bóveda del templo dedicado a San IIdefonso y todavia son visitadas hoy con mucho afán en Alcalá (37).

\section{LO8 AÑOS DIFICILES}

El efecto psicológico de aquella victoria tuvo efectos contrarios entre moros y cristianos. Los primeros, aterrados ante la aplastante derrota que habían sufrido, se apresuraron a pactar con el rey Católico una paz o una tregua. Así, a partir de la conquista de Orán, acaecida el día de la Ascensión del Señor del año de 1509 , se entrega la ciudad de Bujía, a primeros de 1510. Argel que. hasta entonces, pagaba tributos a Bujía, pasó al vasallaje del Rey de España. Por semejante forma, pasó a manos de España casi toda la costa del norte de Africa, hasta el reino de Túnez, declarándose vasallos suyos Mostaganen, Mazagrán. Tremecén, Tenes, Tedeles y Gigel (38). Aquel mismo año, las tropas de Pedro Navarro conquistaban Trípoli para el Rey de Castilla (39).

Aquí se sitúa el momento más alto de todo aquel proceso. A partir de ahora, sólo asistimos al paulatino declinar de la presencia y el poderío español en el norte de Africa. Cisneros, que había sido testigo directo y, en ocasiones, partícipe activo de aquella empresa, llegó a conocer los primeros contratiempos que debilitaron no sólo la presencia político-militar en el norte africano sino que afectaron también a un fenómeno de más amplia envergadura: la creciente insensibilización del pueblo y de los gobernantes hacia el norte de Africa, territorio importante no sólo como camino para una futura cruzada hacia Tierra Santa sino, sobre todo, 
para librar y asegurar al litoral español de los ataques procedentes de las riberas africanas.

Los factores que incidieron en esta creciente insensibilización fueron amplios y complejos. No fue el de menor importancia la manera en que Fernando el Católico reaccionó a la hora de distribuir el botín obtenido en Orán por las tropas de Cisneros. Este había adelantado importantes sumas de dinero para cubrir los gastos de la expedición. Una vez logrado el éxito, cedió la posesión de Orán bajo la promesa real de reintegrarle los adelantos efectuados. Pareció que esta operación no sería completa si no se entregaba al fisco real al menos la quinta parte de todo cuanto hubiera sido tomado como botín en las operaciones militares. Cisneros afirmaba "que no se había reservado nada de tal botín. excepto algunos libros árabes y algunas cosas más vistosas que útiles, que estaban guardadas en Alcalá como recuerdo de la victoria" (40). Pero estas explicaciones no eximían de entregar la parte correspondiente a todos y cada uno de los que habían combatido en Orán. El Rey envió, en consecuencia, un ejecutor que registró el ajuar de Cisneros y los de todos los particulares que participaron en el botín. La operación se llevó a cabo de una manera despótica e insolente por todos los pueblos del arzobispado de Toledo en los que se habían reclutado los soldados. Las propiedades se habían vendido en su mayor parte a los prisioneros de guerra. Pero todo lo demás, desde los tapices de Marruecos a las fajas de Numidia y, en general, todo cuanto tenía algún valor, entró en el botín. Todo ello se fue acumulando en montones de los que se apartó el quinto correspondiente al rey.

Fue algo enojoso, - se nos dice-, para Jiménez, sobre todo porque resultó cosa injusta e indigna, ya que la mayor parte del ejército se había quedado en Africa... a quienes habia tocado un botín más rico y espléndido. Ahora eran vejados los hombres insignificantes y los labradores que, mientras estuvieron ausentes de sus casas y de sus puestos de trabajo, perdieron en sus bienes familiares más de lo que ganaron con el botín de la guerra (41).

Gran incidencia tuvieron, también, los desastres militares que tuvieron lugar poco tiempo después. Cierta importancia tuvo la derrota 
padecida en las islas Querquenas, en la que pereció Jerónimo Vianello con todos sus hombres (42). La más grave fue, sin embargo, la que se sufrió en la isla de Gelbes el veintiocho de agosto de 1510, fecha que, mucho tiempo después, calificaría Alvar Gómez como "triste y aciaga todavía para los nuestros", hasta tal punto que aquella tierra fue "considerada infame por la derrota de los españoles, execrada y llena de imprecaciones como nefasta para los nuestros" (43). En ella

murieron cerca de cuatro mil egregios soldados con sus tribunos y jefes, algunos a hierro; muchos, por la sed y sumergidos en las cuevas movedizas de la tierra arenosa (44).

La derrota de la isla de Gelbes marcó la conciencia colectiva española en el futuro. De inmediato, sin embargo, no arredró a Fernando ni a Cisneros. Inmediatamente se puso en marcha la preparación de una gran armada, destinada a vengar el desastre.

Conmovido profundamente el ánimo del rey por el desastre de los Gelbes... determinó preparar en Cádiz una numerosa y muy esforzada armada, para pasar él mismo al Africa un poderosisimo ejército y vengar así con gran devastación de los enemigos la muerte causada (45).

Inmediatamente ordenó llamar a Cisneros, disponiendo que se acercara hasta Sevilla. porque no quería pasar sin el apoyo de su autoridad y su consejo. Al divulgarse por España la noticia de la expedición que el rey preparaba "hubo gran concurrencia de toda clase de gentes a Sevilla, pues acudieron no sólo los Grandes, sino también prelados y sacerdotes principales, para acompañar, con ánimo dispuesto y deseo ardoroso, al rey a una guerra tan justa" (46).

En aquella precisa coyuntura, sin embargo, nuevos acontecimientos se produjeron en Europa. El rey de Francia, apoyándose en un grupo de Cardenales rebeldes, estaba tramando, en Pisa, una conjuración contra el Papa. Fernando, que se consideraba por los pactos contraídos 
defensor y protector máximo de la autoridad pontificia, juzgó todo aquello vergonzoso $y$, por consiguiente, reflexionó sobre este problema con Jiménez y con todos los Grandes y Obispos que habian acudido a Sevilla. Respondieron todos que en vano buscaban guerras exteriores contra los enemigos de la religión, cuando en casa era atacada la cabeza de nuesira religión en luchas internas. Por lo mismo, cambiando de parecer, retrocediendo del mismo umbral de Africa, dirigió sus fuerzas y sus armas a Italia (47).

La empresa había quedado frustrada. Sin embargo, la fama del poderío de la escuadra que se preparaba en Cádiz provocó todavía algunas reacciones de sumisión por parte de los moros, como el Rey de Túnez, que se sometió también a Fernando. Con ocasión de la visita de las delegaciones enviadas por los régulos norteafricanos: se nos cuenta que Cisneros "gozó mucho... pues con ello se convencía de que brillaba cada día más el fruto de su trabajo" y porque

... la raza antes ansiosa en extremo de nuestros despojos, ahora, por temor a las fuerzas españolas, se habia sometido con ánimo dispuesto y humilde a nuestro rey. Debe preferirse esto, —decía-, a haber vencido a toda el Africa con las armas y con muertes (48).

Con diversa fortuna, fueron pasando los años hasta que Cisneros, achacoso y trabajado por los problemas de su regencia, enfermó gravemente cuando se disponía a encontrarse con el Rey Carlos, recién llegado a Castilla. Al saberse su enfermedad

se exendió este rumor a la Bética, de donde pasó a Africa... Los mauritanos, convencidos de que, al estar Jiménez enfermo, todo quedaría descuidado, intentaron devastar las cosas próximas a Granadas. Los turcos, que acababan de tomar Argel, yendo como jefe Horuch Barbarroja, atacaron con fuerte ejército a Orán, honra 
y prez de Jiménez, anunciando que pronto la iban a conquislar (49).

De momento, lo único que salvó la presencia española de un ataque delinitivo de los turcos, apoyados por Barbarroja. fue el temor de los propios berberiscos a ser dominados por la Sublime Puerta. Se supo en efecto que los númidas, "temerosos del poder y fiereza de los turcos, los habían atacado cuando se dirigían a Orán y los habían derrotado en el combate, liberando a los nuestros de aquella preocupación incesante" (50).

Moría así Cisneros en los umbrales de una nueva era. Los nuevos gobernantes de España, muertos ya Fernando y el arzobispo de Toledo, no volvieron a sentir la misma preocupación que aquéllos habían tenido por las cosas de Africa. El tropismo que España entera había mostrado hacia el Mediterráneo se orientó hacia otros rumbos, en parte hacia Europa, en parte hacia la recién descubierta tierra del Nuevo Mundo. Ni siquiera en los momentos en que Carlos $V$ conquistó Túnez o cuando intentó la conquista de Argel, vibraron los espanoles ante Africa de la forma en que lo habían hecho en los días de Cisneros. Al fin y al cabo, aquellas hazañas imperiales se llevaron a cabo pensando más en la seguridad italiana que en la seguridad de nuestras propias costas. Desde entonces hasta ahora. la historia no ha hecho más que repetirse. 
1. De rebus gestis a Firucisco Kimenio Cisnerio, Archiepiscopo Tolelano, libri octo, Alruro Gomecio Toletano authore. (ompluti, Auud Andream de Angulo, 1569. Hemos utilizado la traducción realizada por José Oroz Reta, publicada bajo el título De las IIazañas de Francisco Jiménez de Cisneros. Madrid. Fundación Lniversiania Española. 1984. A esta obra remitimos en nuestras citas. refiriéndonos a las iniciales del autor (AGC) e indicando, a continuación de las mismns, la página o páginas correspondientes de la Iradueción de Oroz.

2. AVII.ES, M.: "Ir a lierra de moros", un sueño frustrado de los misticos aspanioles en Congreso Internacional "el Estrecho de Gibraltar. Couta-noriembre 1957, t. III. Madrid. UNED. $1988.69-75$.

3. NGC 43.- Explica Gómez de Castro cómo Cisneros queria imitar. con aquel gesto. lo que creía que habia hecho su padre San Francisco. del que se decía que pensando en ir a tierra de moros, había venido hasta España.

4. II), Ibidem.

5. "Realizó algunas cosas llevado de la pasión más que de la prudencia. como el bautizo de los moros de Granada o la conquista de Africa”. ACC 531.

6. ACLX̃A. H. de: larias poesias. XCIV. versos $1.2 .3 \times 8$.

7. IIERRERA. II. A. de : Breve dispula de las ocho levadas contra Aristótil y' sus secunces. ed. de París, 1920, Prólogo, pág. 49.

8. ACC 208.

9. ACG 209-210.

10. AGC 208

11. AGC 73.

12. $\mathrm{ACC}: 1+1$

13. $\operatorname{AGC} 251$.

14. AGC: 258

15. ACG; 30,

16. ACC 281.

17. El teslamento se puede ver. entre otras varias publicaciones. en J. MARIA.VA. Historia de España, ed. de Valencia o en DORNER, Discursos norios de Historia. Citado por I. M. DOUSSINAGLE, La política infernariomal de fiernando el Calólico. Madrid, España-Calpo. 1944, púg. 124.

18. $\mathrm{AGC} 250$.

19. $\mathrm{ACC}: 251$.

20. Compendio historial, lil). XX. cap. VIl. Doussinague, siguiendo tanto a Mlvar Gómez como a Quintanilla y Vallejo, considera que, si bien el cardenal Cisncros puso todo su encareci- mienco en recomendar al guerra de Afriena a Fermando el Cácólico, no partió de él la primern iniciativa de ir a Mazalquivir, sino que este proyecto estaba va en estudio cuando intervino el Arzobispo de T'oledo, ID, o.c., pág. 130.

21. DOLSSINAGLE. J. M. o.c. pág. 1:3?.

22. AC, $: 2: 59$.

23. AC, : 201 .

24. Asi lo ruenta el canónigo salmantino Pedro de Torres en sus Apuntamientos históricos.

25. ACC: :30.

26. C.T. A. M. CLII.ARTE. Antonio de Acuña, Madrid, 1986.

27. A Juan de Cazalla encargi (isneros de redactar las cartas en las que se divulgaron los detalles de la batulla y la noticia de la victoria. Era hermano de la ahumbrada María de Cazalla y autor de Lumbre del alme, libro incluido en el Indice de libros prohilides por sospechas de alumloradismo.

28. $A$ C.C: 262 .

29. Después de la victoria, Cisnerus lienció a codos estus labradores, tan numerosos que su falta había dejado sin segadores a las lierras de sa juriselicesión, por lo que su regreso se lunciu necesario si querían recogerse las mieses ya en sazón. AC(: 304. algunos guadalajareños. enrolados en el ejército y poco habituados a guardar la ordenanza de combute. salen de filas (leseosos de llevar a cabo anses que ninguno alguna hazaña valiente". caen en poder de los moros (AC(: 282).

30. AC,C: 288.

31. AC, : :287-288.

32. $A(;:: 278-279$

33. ACC: 290.

34. AC, :321 y 298.

35. Ac;: 301 .

36. ACC: $: 291$.

37. $\mathrm{A}(; \mathrm{C}: 30 \mathrm{3}$.

38. DOLSSIXNGLE. J. M.. Politica imernaciomal.... paig. 227. Cifr. $A C C: 3+5-3+6$.

39. AC::312.

40. ACC: 322.

41. $\Lambda(, 0 ; 323-324$.

42. $\Lambda C,: 31: 3-314$.

43. $\mathrm{AC},(: 315)$

44. AC,. Hidem.

45. IC(: :338.

46. $.16(: ; 339$.

47. $\mathrm{AC}:(: ;+1$.

48. $\lambda(;: 3+3)$.

49. $\lambda(;(; 523-i) 2+$.

50) $A(C, 515$ 